\title{
The dentary of Wareolestes rex (Megazostrodontidae): a new specimen from Scotland and implications for morganucodontan tooth replacement
}

\author{
ELSA PANCIROLI I,2, ROGER B. J. BENSON ${ }^{3}$, STIG WALSH ${ }^{2}$. \\ ${ }^{1}$ School of Geosciences, University of Edinburgh, Grant Institute, Kings \\ Buildings, Edinburgh EH9 3FE United Kingdom; email: elsa.panciroli@ed.ac.uk
}

${ }^{2}$ National Museum of Scotland, Chambers St, Edinburgh EH1 1JF, United Kingdom, email: $\underline{\text { s.walsh@nms.ac.uk }}$

\begin{abstract}
${ }^{3}$ Department of Earth Sciences, University of Oxford, South Parks Road, Oxford OX13AN, United Kingdom, email: roger.benson@earth.ox.ac.uk
\end{abstract}

\begin{abstract}
The Middle Jurassic morganucodontan, Wareolestes rex, was previously known from only four isolated molars from Kirtlington, England. There has been debate over the position of the holotype tooth as an upper or lower molar. We describe a new Wareolestes specimen from the Kilmaluag Formation of Scotland: a partial left dentary with two erupted molars, one unerupted molar, and three unerupted premolars. Empty alveoli for a canine, p1 and p3 are also present. Through detailed comparison of the morphology of the holotype and our new material, we support the original diagnosis of the holotype Wareolestes as a
\end{abstract}


lower molar, most likely $\mathrm{m} 1$. The position of erupted and unerupted replacement teeth in the newly discovered specimen supports a diphyodont pattern of tooth replacement of premolariform dentition in Wareolestes, as suggested for other morganucodontans such as Morganucodon, Megazostrodon and Dinnetherium. However, damage to the dentary means questions remain regarding the sequence of replacement in Wareolestes along the tooth row.

Key Words: Wareolestes rex, Morganucodonta, Megazostrodontidae, Middle Jurassic, Scotland, molar replacement

Morganucodontans are a diverse clade of proximate stem-group mammals known from the Late Triassic until at least the Middle Jurassic, and possibly as late as the Early Cretaceous (Butler et al. 2012). They were among the most abundant early mammaliaforms, and became globally distributed by the Early Jurassic, with fossils known from the USA (Jenkins et al. 1983), India (Datta \& Das 1996), South Africa (Crompton 1964), Greenland (Jenkins et al. 1994), China (Kermack et al. 1973; Young 1978; Luo \& Wu, 1994), Russia (Gambaryan \& Averianov 2001), and across Europe (UK: Kermack et al. 1973; Freeman 1979; Clemens 2011; Switzerland: Clemens 1980; France: Sigogneau-Russell 1983; Evans \& Milner 1994; Debuysschere et al. 2015).

Morganucodontans provide important information on the evolutionary assembly of mammalian anatomy as they possess derived mammalian characters, 
including diphyodont replacement of the antemolar teeth (incisors, canines, premolars) (Crompton 1974; Luo et al. 2004). Diphyodont replacement was argued for the second molar of Megazostrodon (Gow 1986), but this has subsequently been debated (Luo et al. 2004). As in crown-group mammals, morganucodontans also exhibited precise molar occlusion. However, full occlusion was achieved through enamel wear rather than precise occlusion upon tooth eruption (Mills 1971; Crompton 1974; Crompton \& Luo 1993; Luo et al. 2004). Alongside these mammalian synapomorphies, morganucodontans also retained plesiomorphic character states, such as the linear, mesiodistal alignment of the main cusps of postcanine teeth, retention of a post-dentary trough, and an anteriorly positioned angular process of the dentary (KielanJaworowska et al. 2004).

Morganucodonta (Kermack et al. 1973) includes two families: Morganucodontidae and Megazostrodontidae (Stucky \& McKenna 1993; KielanJaworowska et al. 2004). Megazostrodontidae (Gow 1986), was erected to include Megazostrodon and Dinnetherium, and is diagnosed by the reduction of the angular process, flaring of the ridge of the dentary condyle, and the welldeveloped labial cingulum on the upper molars, with the labial cingulum tends to differentiate into a posterior and anterior lobe (Gow 1986; Kielan-Jaworowska et al. 2004). Following the initial description of Megazostrodontidae, Brachyzostrodon (Late Triassic, France and Greenland; Sigogneau-Russell 1983), Indozostrodon (Early Jurassic, India; Datta \& Das 1996, 2001) and 
Wareolestes (Middle Jurassic, England; Freeman 1979) were referred to Megazostrodontidae by these subsequent authors. It should be noted that Indozostrodon may be a junior synonym of Indotherium (Prasad et al. 2006), which was assigned to Morganucodontidae by Prasad and Manhas (2002), and more complete material is required to resolve this.

Wareolestes rex was erected as a new genus and species by Freeman (1979) for a single well preserved molar tooth discovered at Kirtlington cement quarry, an exposure of the Middle Jurassic Forest Marble Formation in Oxfordshire, UK, which has yielded multiple representatives of early mammaliaform groups (Freeman 1976, 1979; Kermack et al. 1998; Sigogneau-Russell 1998, 2003; Butler \& Hooker 2005). Until now, Wareolestes has been known only from the type molar, NHMUK PV M36525, and some referred molar fragments (see below) (Freeman 1979; Butler \& Sigogneau-Russell 2016).

In 2015, field work in the Middle Jurassic Kilmaluag Formation of the Isle of Skye, Scotland recovered a dentary with multiple erupted and non-erupted teeth that we attribute to Wareolestes rex. This is the first occurrence of this genus in Scotland. The specimen was found at a coastal locality, with the buccal side of the jaw exposed and therefore slightly abraded. Nevertheless, it retains evidence of at least three replacement teeth and three permanent molars. The new specimen therefore provides crucial evidence for the mode of dental replacement in megazostrodontids. It also adds to our knowledge of the anatomy of 
Wareolestes: it clarifies the previously disputed position of the holotype for this genus (Hahn et al. 1991; Butler \& Sigogneau-Russell 2016), and adds a new feature that we consider to be an autapomorphy: the presence of a labial cingulid. Finally, it adds to a growing list of mammaliaforms known from the Bathonian (Middle Jurassic) Kilmaluag Formation of Scotland (Waldman \& Savage 1972; Savage 1984; Clemens 1986; Evans \& Milner 1994; Close et al. 2015), allowing comparisons with the well-sampled Middle Jurassic mammaliaform assemblage of England.

\section{MATERIALS AND METHODS}

The new specimen NMS G.2016.34.1 was scanned at $95 \mathrm{kV}$ and $225 \mu a$ using a Nikon XT H 225 ST micro-CT scanner at the University of Cambridge Biotomography Centre (http://www.cbc.zoo.cam.ac.uk/) with an isotropic voxel size of $13.4 \mu \mathrm{m}, 1998$ slices at export. The density of the metamorphosed limestone matrix limited the resolution of the scan. The fossil was segmented from the matrix using Mimics 19.0 (Materialise, Leuven, Belgium). The specimen was also examined directly using a Meiji Techno RZ3361 microscope. The holotype was scanned on the same equipment at $75 \mathrm{kV}$ and $80 \mu \mathrm{a}$, with an isotropic voxel size of $3 \mu \mathrm{m}, 866$ slices at export. It was also digitally reconstructed using Mimics 19.0. 


\title{
TERMINOLOGY
}

We follow the dental cusp terminology of Crompton (1974) (Figure 1).

Morganucodontans possess three main cusps, $a / A, b / B$ and $c / C$, aligned anteroposteriorly in a triconodont pattern. There is also a distal cingulid cusp $d / D$, aligned with the three main cusps, and a series of cingulid cusps which can include mesial cusp e/E and midline cusp $g / G$ (= the kühnecone; Parrington 1967), not aligned with the main $a-d$ cusp row. Cusps are referred to in lower case for lower molars, and upper case for the upper molars. The terms labial and buccal are used synonymously.

Institutional abbreviations. NMS, National Museum of Scotland, Edinburgh, UK; NHMUK, Natural History Museum, London, UK.

\section{SYSTEMATIC PALAEONTOLOGY}

\author{
MORGANUCODONTA Kermack, Musset and Rigney, 1973 \\ MEGAZOSTRODONTIDAE Gow, 1986
}

Wareolestes Freeman, 1979

Type and only species. Wareolestes rex Freeman, 1979 
Wareolestes rex Freeman, 1979

Holotype. NHMUK PV M36525; right or left, lower or upper molar from Kirtlington Mammal Bed, Forest Marble Formation (Bathonian, Middle Jurassic), Kirtlington Cement Works Quarry, Oxfordshire, England. A 3D digital model of this specimen in .stl format, and our CT tomographs, are available in the Panciroli et al. 2017.

\author{
Referred material. NHMUK PV M46240, NHMUK PV M46248, NHMUK PV \\ M46775 (Freeman 1979; Butler and Sigogneau-Russell 2016), all isolated molars \\ from the Late Bathonian of Kirtlington, Oxfordshire, UK; plus NMS G.2016.34.1 \\ from the Bathonian Kilmaluag Formation of the Isle of Skye, Scotland. The \\ presence of an unerupted molar m3 indicates that NMS G.2016.34.1 represents \\ a sub-adult. A 3D digital model of NMS G.2016.34.1 in .stl format, and our CT \\ tomographs, are available in Panciroli et al (2017). Re-identified specimens \\ previously referred to Wareolestes include NHMUK PV M46563 (re-identified as \\ Gobiconodon sp. indet (Butler \& Sigogneau-Russell 2016)) and NHMUK PV \\ M46811 (now the holotype of Cherwellia leei (Butler \& Sigogneau-Russell 2016)), \\ both from the Late Bathonian of Kirtlington, Oxfordshire, UK.
}

Previous diagnosis. Wareolestes rex is a megazonstrodontid morganucodontan (sensu Kielan-Jaworowska et al. 2004) with dental morphology that is congruent 
with other members of Morganucodonta: three principle cusps arranged anteroposteriorly along the tooth row (cusps $a / A, b / B$, and $c / C$ ). Megazostrodontidae is diagnosed by a reduced angular process, flared ridge of the dentary peduncle, the division of the upper labial cingulum into anterior and posterior lobes and the presence of well-developed labial cingular cusps in the upper molars. Wareolestes shares with some morganucodontans a central cusp a/A larger than the other cusps (as in Morganucodon), and a wrinkled enamel surface (as in Brachyzostrodon) (Kielan-Jaworowska et al. 2004).

Autapomorphies of Wareolestes are the placement of cusp $g$ bucco-lingually in line with cusp a, and a poorly defined labial cingulum.

Revised diagnosis. In addition to the above, a new autapomorphy of Wareolestes rex is the presence of a labial cingulid in the lower molars, with cusp $g$ buccolingually in line with cusp a, and a poorly defined lingual cingulid. The dental formula is ?.1.5.3/?.1.5.3.

Locality and horizon of NMS G.2016.34.1. The specimen comes from the Straithaird Peninsula north of Elgol and approximately $1 \mathrm{~km}$ south of Cladach a'Ghlinne (see Close et al. 2016). It was found in a fallen boulder, below the tide line. Although not in situ, it can be identified as having come from the Kilmaluag Formation. The Kilmaluag Formation is part of the Middle Jurassic Great Estuarine Group of the Hebrides Basin. This Group comprises a complex series of sediments of mostly non-marine origin with minor marine horizons that indicate basin subsidence and marine transgression (Barron et al. 2012). The Kilmaluag 
Formation itself comprises argillaceous limestones and calcareous mudstones, with desiccation cracks, formed by ephemeral lagoonal environments that periodically dried out to form mudflats (Hudson 1980; Andrews 1985). The Kilmaluag Formation is Bathonian, as are similar deposits in England, although exact biostratigraphical correlations between the English sites and exposures of the Kilmaluag Formation have proven difficult (Barron et al. 2012). The specimen reported here was found in an argillaceous micritic limestone.

\section{Description}

NMS G.2016.34.1 is a partial left dentary, missing its anterior portion from c/p1 anteriorly (Figures 2-3). The dentary condyle and coronoid process are also missing posteriorly. Portions of several erupted and unerupted teeth are present, and are described below. The specimen is partially embedded in matrix, so description of the lingual surface is based on digital reconstructions from $\mu \mathrm{CT}$ scans.

The dentary, as preserved, measures $22.3 \mathrm{~mm}$ anteroposteriorly, with a maximum buccolingual width of $1.82 \mathrm{~mm}$, measured at the level where $\mathrm{m} 2$ abuts m3. However, the dentary is crushed just posterior to this, and it is possible that it was slightly wider ventral to $\mathrm{m} 3$. It is $3.23 \mathrm{~mm}$ in dorsoventral depth from the ventral surface of the dentary to the alveolar margin at $\mathrm{m} 2$. 
We identify the preserved tooth portions as being a partial, unerupted p2 and roots of dp2, unerupted $\mathrm{p} 4$ and $\mathrm{m} 3$, an erupted $\mathrm{m} 1$ (damaged), and an erupted m2 (damaged lingually). There is also a fragment of an unerupted p5. Empty alveoli for c, p1 and p3 are present. Based on this information, we estimate a dental formula of ?.1.5.3/?.1.5.3. Both Megazostrodon and Dinnetherium have five molars (Gow 1986; Kielan-Jaworowska et al. 2004), but there is no indication of a fourth or fifth molar in NMS G.2016.34.1 (Figure 3), nor is there space in the dentary for further molars to form posterior to $\mathrm{m} 3$. We assume there was one canine in NMS G.2016.34.1, and a partial alveolus remains at the preserved anterior end of the dentary, however we are unable to determine incisor count because the anteriormost portion of the specimen is missing.

Identification of premolars and molars in NMS G.2016.34.1 was based on the replacement pattern evidenced by the position of replacement teeth within the dentary (see below). A distinct change in morphology between the posteriormost premolar and anteriormost molar has been observed in other morganucodontans (Kielan-Jaworowska et al. 2004). Compared to m1, the posteriormost premolar (p5) of Megazostrodon rudnerae has a taller cusp a (dorso-ventrally) and less well developed cusps $b$ and $c$, and $\mathrm{m} 1$ has a more prominent cingulid and taller cingular cusps than $\mathrm{p} 5$ (Crompton 1974). Only a small portion of $\mathrm{p} 5$ is preserved in NMS G.2016.34.1, however, this preserved portion appears to be the anterior projection of a cingulid, indicating a molarised morphology for p5 in Wareolestes rex (Figure 4B). The morphology of the preserved portion of $\mathrm{p} 5$ is not congruent 
with a remnant of root, as it is not hollow along its length (unlike a root), nor does it resemble the sharp anterior portion of the p4 crown. Therefore, we identify it as the anterior projection of the cingulid, and suggest p5 in Wareolestes is somewhat molarised.

The morphology of p4 is distinctly different from the molars, having a proportionally taller cusp a compared to cusps $b$ and $c$. Although its roots are absent, the preserved ventral portion of p4 and the morphology of its alveolus indicate that it was double-rooted.

The premolar we identify as dp2/p2 in NMS G.2016.34.1 is double rooted, while the alveoli anterior to dp2/p2 are single rooted (Figure 4A). In Megazostrodon rudnerae the first two premolars are single rooted, and the posterior three double rooted (Gow 1986). If this was the pattern in Wareolestes, it would suggest a premolar count of six - more than any other morganucodontan. Although it is possible that the premolar count may be higher than any other genus, it is more likely that Wareolestes has a different root pattern than Megazostrodon. We therefore suggest the anterior most alveoli to be $c$ and $p 1$, and identify the anteriormost double rooted premolar present in NMS G.2016.34.1 as dp2/p2.

The remnants of dp2 include the lingual half of its double roots, and a small portion of the crown where it meets the roots. Ventral to this, between the root 
remnants, is the cusp a tip of a replacement tooth p2 (Figure 3). This forms a hollow cone, and the rest of $\mathrm{p} 2$ has either not formed or has been lost.

The dentary is fractured just anterior to the inferred position of the angular process. Although the angular process itself is not preserved, the mandibular body ventral margin anterior to the angular process is preserved. This surface is uniformly convex anteroposteriorly, albeit slightly, as in the intact dentaries of Megazostrodon and Dinnetherium (Jenkins et al. 1983; Gow 1986; KielanJaworowska et al. 2004). There is no sign of the sigmoidal curvature typically associated with the ventral projection of an angular process, as seen in Morganucodon, Hadrocodium, and in other taxa with well-developed angular processes (Kermack et al 1973; Crompton \& Luo 1993; Luo et al. 2001). We suggest that Wareolestes possessed a reduced angular process, termed a 'pseudangular' by Jenkins et al. (1983). Due to lack of preservation it is not possible to assess if the angle of Wareolestes would have been slightly inflected, as in Hadrocodium (Luo et al. 2001).

The ventral margin of the masseteric fossa is visible buccally on the posteroventral portion of the dentary, and there is some buccolingual crushing and abrasion of this feature (Figure 3). The dentary is crushed ventral to $\mathrm{m} 3$, but the preserved morphology suggests it was bucco-lingually widest at this point of the jaw, as in Megazostrodon (Gow 1986). The Meckel's sulcus is present on the ventrolingual surface of the dentary. The sulcus extends from the crushed 
section of dentary ventral to $\mathrm{m} 3$, to the base of $\mathrm{p} 5$. Examination of the X-ray CT data indicates that the Meckel's sulcus is crushed transversely, causing the lingual surface of the dentary to collapse buccally towards the mandibular canal, an internal neurovascular canal inside the mandibular body.

The ventral surface of the dentary is more strongly convex anteroposteriorly than in either Megazostrodon or Dinnetherium, but is closest in curvature to the latter (Figure 2) (Gow 1986; Kielan-Jaworowska et al. 2004). This curvature is consistent with the presence of a reduced angular process (as in Dinnetherium), and is accentuated by the dorsal curvature of the anterior portion of the dentary, particularly anterior to $\mathrm{p} 5$. This curvature is unlike the straighter morphology seen in most other morganucodontans, or in closely related groups such as Docodonta, but resembles some eutricodontans such as Phascolotherium, and later eutherians such as Kennalestes (Kielan-Jaworowska et al. 2004). This similarity is probably functional, resulting from convergent evolution; we do not infer a close relationship between these taxa and Wareolestes.

The coronoid crest rises posterodorsally from just posterior to the unerupted $\mathrm{m} 3$. The dentary is broken posteriorly, so the coronoid process is missing. It is likely that Megazostrodon possessed a coronoid facet that articulated with the coronoid bone just posterior to the ultimate molar. However, this facet is not evident in NMS G.2016.34.1 due to crushing on the lingual surface of the dentary. Despite crushing, the postdentary trough is clearly visible, as in other morganucodontans, 
and other stem mammals with the primitive character of retaining post-dentary bones (Kielan-Jaworowska et al. 2004; Luo 2011; Meng et al. 2015). It is smaller than in Morganucodon, closer in morphology to Dinnetherium (KielanJaworowska et al. 2004). Ventral to m3, just ventral to mid-height on the buccal surface of the dentary, abrasion has revealed two small windows into the mandibular canal for the nerves and vessels in the interior of the dentary. This has been digitally reconstructed along some of the length of the dentary (Figure 4) - although crushing and abrasion prevent full reconstruction of this feature.

Anterior to $p 5$ the dentary flares lingually, forming the mandibular symphysis. However, because the dentary is broken anterior to the remnants of the alveoli of $\mathrm{c} / \mathrm{p} 1$, few morphological details of the symphysis are evident. Foramina are visible anteriorly on the ventrolingual surface of the symphysis, immediately posterior to its broken anterior portion, around the level of $\mathrm{dp} 2 / \mathrm{p} 2$. There are at least two foramina, positioned approximately below $\mathrm{c}$ and pm1.

The most completely preserved molar tooth is $\mathrm{m} 2$. As in the holotype molar, NHMUK PV M36525, the central cusp a of m2 in NMS G.2016.34.1 is higher dorso-ventrally than cusps $b$ and $c$. Cusp a also has distinct dorsoventral ridges on the posterior and anterior surfaces, with corresponding troughs, and there is an expanded labial cingulid that curves around the posterior edge of the tooth. The cingulid bears a prominent cusp $d$, and the cingulid continues onto the labial and lingual surfaces of the tooth. Damage to the buccal side of $\mathrm{m} 2$ in NMS 
G.2016.34.1 means the highest cingular cusp $g$ is not preserved. In the holotype (NHMUK PV M36525), cusp $g$ is directly lingual to cusp a, unlike in Morganucodon, Megazostrodon, and upper molars of Brachyzostrodon (Freeman 1979; Hahn et al. 1991)). The double roots of $\mathrm{m} 2$ are deep in NMS G.2016.34.1, extending close to the ventral surface of the dentary, and are not clubbed at their ventralmost point.

The other molar teeth of NMS G.2016.34.1 are less complete, and show morphologies that are congruent with that of m3. Cusps $c$ and $d$ are still present on $\mathrm{m} 1$, but $a$ and $b$ are missing, as is the lingual cingulid. The ridge extending from cusp $d$ forms the posterior cingulid, which curves onto the lingual side of the tooth. The roots of $\mathrm{m} 1$ do not diverge as they extend ventrally, unlike in $\mathrm{m} 3$. Instead, they converge at their ventral ends, and they are slightly longer than in $\mathrm{m} 2$. Also, the lingual surface of $\mathrm{m} 1$ appears slightly flatter than that of $\mathrm{m} 3$.

Cusps $a, b, c$ and $d$ are visible in $\mathrm{m} 3$, despite the tooth being somewhat fractured. This tooth is longer anteroposteriorly than either m1 or m2 (Table 1). The distinct dorsoventral ridges and embayments seen in $\mathrm{m} 2$ and the holotype of Wareolestes rex are also visible in $\mathrm{m} 3$. There is no root present in $\mathrm{m} 3$.

\section{DISCUSSION}

Referral of NMS G.2016.34.1 to Wareolestes rex 
NMS G.2016.34.1 is undoubtedly a morganucodontan: it retains the anteroposterior linear arrangement of the molar cusps that distinguishes morganucodontans from kuehneotheriids. Furthermore, like all other morganucodontans, it retains the postdentary trough and has diphyodont tooth replacement in the preserved premolar positions. This can clearly be seen by the presence or inferred presence of replacement teeth (Crompton \& Luo 1993; Luo et al. 2004; Kielan-Jaworowska et al. 2004) (see below).

Wareolestes was placed in Megazostrodontidae by Hahn et al. (1991) and subsequently by Kielan-Jaworowska et al. (2004). We refer NMS G.2016.34.1 to Megazonstrodontidae because we infer that it had an apomorphic reduced angular process (the 'pseudangular') as seen in Megazostrodon (Crompton 1974) and Dinnetherium (Jenkins et al. 1983). We cannot state whether it also shares the flaring of the dentary peduncle, as this is not preserved in NMS G.2016.34.1, nor the lobed upper molars and well developed cingular cusps, as no upper molars were recovered with NMS G.2016.34.1. However, as we consider this specimen to be referable to Wareolestes (see below), these features may be inferred as having been present based on their presence in other megazostrodontids.

We refer NMS G.2016.34.1 to Wareolestes based on the following apomorphies shared with the holotype: a substantial cusp $d$ positioned directly distal to cusp $c$ 
on a labial cingulid that curves around the posterior of the tooth and continues onto the lingual surface. Like the holotype, it also has wrinkled enamel on cusp a, a feature shared with Brachyzostrodon and Helvetiodon, but that distinguishes it from Megazostrodon. We also consider the overall structure and appearance of the tooth to be highly consistent with the holotype of Wareolestes (see above and Figure 5). As in the holotype molar, cusp a is proportionally longer anteroposteriorly than in Morganucodon, and has distinct dorsoventral ridges on its posterior and anterior surfaces, with corresponding troughs, producing shallow 'embayments' (Freeman 1979; p. 160). Kielan-Jaworowska et al. (2004; p. 182) noted that the holotype tooth of Wareolestes rex is 'one-and-a-half times [the size of] most morganucodont teeth.' The m2 of NMS G.2016.34.1 is larger than the holotype (see Table 1 and Figure 6) and close in size to Brachyzostrodon maior and Helvetiodon schutzi (Table 1; Figure 6; it is slightly anteroposteriorly shorter and bucco-lingually wider than the $\mathrm{m} 3$ teeth of those taxa). The $\mathrm{m} 1$ and $\mathrm{m} 3$ are also large (though smaller than the holotype). The largest morganucodontid currently known is Paceyodon davidi (Clemens 2011), the known molar of which is approximately $20 \%$ larger than $\mathrm{m} 3$ in NMS G.2016.34.1.

The holotype of Wareolestes rex has an enlarged cusp $g$ and subequal cusps $b$ and $c$, distinguishing it from the megazostrodontid Dinnetherium, in which cusp $g$ is not enlarged, and cusps $b$ and $c$ are approximately equal in height. While cusp $g$ is missing in NMS G.2016.34.1, it shares the slight elevation of cusp $b$ compared to cusp c. Finally, it differs from Indozostrodon in having a larger cusp 
$a$ - this cusp is smaller, positioned more posteriorly and twinned with cusp $c$ in Indozostrodon.

\begin{abstract}
A previously cited difference between Morganucodon and Megazostodon is the manner of occlusion of the molar cusps. In Morganucodon it was thought that cusp a occludes between cusps $A$ and $B$ on the opposing upper molar, known as offset shearing (Crompton \& Jenkins, 1968; Mills 1971). In Megazostrodon cusp a was stated to occlude between cusp $B$ of the opposing upper molar, and cusp C of the preceding upper molar, called embrasure shearing (Crompton 1974). However, recent preliminary work suggests that in Morganucodon at least, shearing patterns may be more variable along the tooth row than previously understood (Jäger et al. 2016).
\end{abstract}

Positions of isolated Wareolestes teeth within the tooth row

NMS G.2016.34.1 provides information about the positions of previously reported, isolated teeth of Wareolestes within the tooth row, and their taxonomic identifications. Since the initial description of Wareolestes, there has been disagreement about whether the holotype is an upper or lower molar (Hahn et al. 1991; Kielan-Jaworowska et al. 2004). The holotype of Wareolestes rex NHMUK PV M36525 was described as a lower molar by Freeman (1979), but Hahn et al. (1991) and Butler and Sigogneau-Russell (2016) suggested that it may be an 
upper molar, due to the presence of what appears to be a labial cingulum with 'well developed labial cingular cusps' (Kielan-Jaworowska et al. 2004; p. 179). Both of these features have been considered diagnostic for megazostrodontid upper molars, alongside partitioning of the labial cingulum into anterior and posterior lobes (Kielan-Jaworowska et al. 2004). If NHMUK PV M36525 represents an upper molar, then the surface considered to be the buccal side by Freeman (1979) would be the lingual side (Butler \& Sigogneau-Russell 2016) (Figure 1).

Thanks to the in situ placement of molars within the dentary in NMS G.2016.34.1, we can clarify the absence of a continuous lingual cingulid in the lower molars of Wareolestes rex. Unfortunately, the labial portion of the cingulid is not preserved in any of the molars of NMS G.2016.34.1. The specimen therefore provides no information on the morphology of the labial cingulid in Wareolestes. We cannot therefore, compare these cingular structures with those of the holotype to evaluate the status of the holotype (NHMUK PV M36525) as an upper or lower molar based on the cingulum/cingulid. Nevertheless, we have re-examined the anatomy of NHMUK PV M36525 using $\mu$ CT scanning (Figure 5). The resulting 3D models show that, due to the absence of enamel in the region of the "labial" cingulum/cingulid (Figure 5A) there is no conclusive evidence for a continuous labial cingulum/cingulid, nor what can be described as 'well developed' labial cingular/cingulid cusps in the remaining dentine. The cingular cusps appear less well developed in NHMUK PV M36525 than they are in the upper molars of 
Megazostrodon (Crompton 1974) or Brachyzostrodon (Hahn et al. 1991) based on the remaining dentine, and more closely resemble the size of the lingual cusps in lower molars of Brachyzostrodon maior (Hahn et al. 1991, figure 2). Therefore, the preserved cingular morphology of NHMUK PV M36525 does not provide strong evidence of identity as an upper molar.

Butler and Sigogneau-Russell (2016) referred a megazostrodontid molar from Kirtlington, NHMUK PV M46775, to Wareolestes sp. indet., identifying it as an upper. They suggested that the dorsoventrally longer cusps of this specimen, compared to the holotype NHMUK PV M46775 may indicate that this represents a distinct species of Wareolestes. We suggest that NHMUK PV M46775 may be an upper molar of Wareolestes rex. We base this on the presence of a prominent cingulid both labially and lingually, more developed "labial" cusps than those in the holotype NHMUK PV M36525, and proportionally dorsoventrally longer cusps (see below) than the holotype. Consistent with this, Butler and SigogneauRussell (2016) suggested that Wareolestes upper molars were transversely wider than the lowers. The morphological difference between NHMUK PV M46775 and the holotype further supports our identification of the holotype as a lower left molar.

The $\mathrm{m} 2$ of NMS G.2016.34.1 strongly resembles the holotype specimen of Wareolestes rex, NHMUK PV M36525 (Figure 5). The $\mathrm{m} 2$ has similar proportions of cusps $c$ and $d$ and the posterior cingulid where it extends onto the lingual side 
of the tooth. The $\mathrm{m} 2$ of NMS G.2016.34.1 has a more expanded posterior cingulid than the cingulids on $\mathrm{m} 1$ or the holotype molar NHMUK PV M36525. The unerupted m3 crown in NMS G.2016.34.1 shows that it had an enlarged posterior portion of the cingulid, also similar to that of $\mathrm{m} 3$ but distinct from $\mathrm{m} 1$ and the holotype molar. This provides strong evidence for variation along the tooth row and suggests that the holotype molar, NHMUK PV M36525 likely represents an m1 lower molar. The lingual cingulid in both NHMUK PV M36525 and m1 and m2 in NMS G.2016.34.1 tapers out directly below cusp a. Gow (1986) described the lower molars in Megazostrodon as having dorsoventrally taller cusps than the uppers; the molar cusp heights are proportionally similar between NMS G.2016.34.1 and NHMUK PV M36525 (Figure 5), consistent with identification of NHMUK PV M36525 as a lower molar.

There are some small differences between NHMUK PV M36525 and the new specimen NMS G.2016.34.1, but most are the result of missing portions of enamel in the former, and the missing labial portion of the latter (Figure 6). For example, NMS G.2016.34.1 at first appears bucco-lingually narrower and the lingual molar surface slightly flatter. However, as we have already identified from differences between $\mathrm{m} 1, \mathrm{~m} 2$ and $\mathrm{m} 3$ in NMS G.2016.34.1, there is variability in tooth morphology along the tooth row. Debuysschere et al. (2015) also noted variability in dental characters among Morganucodonta, such as features of the cingulum, related to position in the tooth row. They recommended such characters should therefore be treated with caution. What remains of the molars 
in NMS G.2016.34.1 supports this assertion. The paucity of megazostrodontid material, lack of enamel on the Wareolestes holotype, damage to the specimens, and intraspecific variation in cusp height and cingulum protrusion, suggests caution in treating these differences as anything other than intraspecific variation, and further supports our identification of NMS G.2016.34.1 as Wareolestes rex.

Brachyzostrodon lacks a distinguishable cusp $g$ on the lower molars (Hahn et al. 1991; Crompton \& Luo 1993; Kielan-Jaworowska et al. 2004). The distinct wrinkling of enamel in Wareolestes and Brachyozostrodon could suggest a close relationship between these genera. However we consider it unlikely that Wareolestes did not possess a cusp $g$ on the lower molars, based on the strong morphological similarity between the holotype (above) - which possesses a cusp $g$ in the apomorphic position buccal to cusp a - and the lower molars in NMS G.2016.34.1.

Pattern of dental replacement in Megazostrodontidae

NMS G.2016.34.1 provides information on the pattern of dental replacement in Megazostrondontidae, thanks to the presence of unerupted and partially erupted premolar and molar teeth, alongside fully developed teeth with complete roots for which no replacement tooth is present (Figure 3). Modes of dental replacement are important for understanding the origins of key aspects of mammalian oral processing. The precise occlusion between upper and lower teeth seen in 
morganucodontans, while still honed by wear after eruption, is closer to the more precise occlusion of the derived mammalian dentition (Kielan-Jaworowska et al. 2004; Luo et al. 2004). Critically, it is likely that such occlusion is only possible when rates of tooth replacement are reduced (i.e. diphyodont or single tooth generations).

It is considered beyond doubt that Morganucodon exhibited diphyodont replacement of antemolar teeth (incisors, canines, premolars) (Mills 1971; Parrington 1971; Crompton \& Luo 1993; Luo et al. 2004). Morganucodontans are considered to be the most basal mammaliaforms possessing this pattern of dental replacement (Mills 1971; Parrington 1973; Luo et al. 2004; KielanJaworowska et al. 2004). This is in contrast to the more stemward mammaliaform Sinocondon, which replaced its premolars once, but replaced the canine at least three times and replaced incisors in an alternating sequence, as in many nonmammalian cynodonts (Crompton \& Luo, 1993; Zhang et al. 1998). There is evidence for the resorption of anterior postcanines in mature individuals of Morganucodon, Eozostrodon and Dinnetherium, without replacement (Mills 1971; Parrington 1971; Crompton \& Luo, 1993). This is a plesiomorphic cynodont characteristic also seen in more basal taxa such as Sinoconodon (Crompton \& Luo, 1993). There is no evidence to indicate such resorption in NMS G.2016.34.1. 
Gow (1986) argued that Megazostrodon, a morganucodontan, also replaced its anteriormost molars. There is clear evidence that among morganucodontans the molars in more posterior positions are never replaced, erupting as the individual reaches maturity as in most modern mammals (Parrington 1971; Crompton \& Parker, 1978; Luo et al. 2004; O’Meara and Asher 2016). The wear facet patterns on many hundreds fragmentary mandibles of Morganucodon watsoni show no evidence of replacement in the posterior molars (Parrington 1971; Young 1982; Crompton \& Luo 1993); with molars frequently heavily worn in larger and older individuals, suggesting they had not been replaced (Parrington 1971). A similar observation has been made in four dentaries of Megazostrodon (Crompton 1974; Gow 1986) and eight dentaries of Dinnetherium (Jenkins et al. 1983). Gow (1986) suggested that Megazostrodon may have replaced its $\mathrm{m} 2$ due to this molar being less worn than $\mathrm{m} 1$ or $\mathrm{m} 3$ in two specimens from the Early Jurassic Elliot Formation, South Africa. However, Luo et al. (2004) considered the sample size too small to be definitive.

Our observations are consistent with the proposition that Wareolestes, a megazostrodontid morganucodontan, did not replace its molar teeth. We find no evidence for replacement for $\mathrm{m} 1, \mathrm{~m} 2$ or $\mathrm{m} 3$ in NMS G.2016.34.1, despite the presence of replacement teeth more anteriorly along the tooth row. The $\mathrm{m} 1$ and $\mathrm{m} 2$ of this specimen have deep and well-developed roots that have not been even partially resorbed, and no portions of any replacement teeth are present at these loci. In contrast, the alveolus of p5 does not contain well developed roots 
or fragments thereof, suggesting that the preserved portion of $\mathrm{p} 5$ was an unerupted replacement tooth (Figure 3). In support of this hypothesis, we note that the preserved portion of $p 5$ is located within the body of the jaw, roughly level with the emerging $\mathrm{p} 4$, indicating that this tooth was developing and erupting from the dentary at approximately the same time as $p 4$.

NMS G.2016.34.1 provides evidence for specifically diphyodont replacement of the premolar teeth in Wareolestes, consistent with observations of Morganucodon (Young 1982; Crompton \& Luo, 1993). Premolar dp2/p2 comprises the roots of an erupted 'milk tooth' with the replacement premolar forming beneath. The alveoli for the deciduous premolars are clearly visible in the dentary, and the p4 remains within the dentary just ventral to the alveolar border.

Nevertheless, the pattern of dental replacement seen in Wareolestes is not identical to that described for Morganucodon. In both Morganucodon, and the more stemward mammaliaform Sinoconodon, premolar replacement occurs in a sequence from anterior to posterior ('antero-posterior replacement'; Crompton \& Luo, 1993; Zhang et al. 1998). However, in NMS G.2016.34.1 both preserved replacement premolars $(p 2, p 4)$, and the preserved portion of $p 5$, are located at approximately equal height within the dentary, indicating that antero-posterior replacement did not occur, or was only weakly manifested. Interestingly, p3 is represented only by an empty alveolus, and it is possible that the absence of a replacement $\mathrm{p} 3$ within the body of the dentary indicates a different timing of 
replacement at this locus. If correct, then this suggests possible alternate replacement of premolars in Wareolestes. Antero-posterior replacement of premolars is considered a derived character for Mammaliaformes (Rowe 1998; McKenna \& Bell 1997). However, some stem therians and eutherian mammals developed alternating premolar replacement (Luo et al. 2004). Due to damage to the buccal side of the dentary, we do not consider there to be conclusive evidence for the sequence of premolar replacement in Wareolestes. As the anterior portion of the dentary is missing, NMS G.2016.34.1 also does not provide evidence on the replacement patterns of incisors or canines in Wareolestes.

\section{CONCLUSIONS}

The megazostrodontan morganucodontid Wareolestes rex was erected for a single molar tooth from Kirtlington in England (Freeman 1979), and until now only four isolated molariform teeth we referred to $W$. rex. Our new specimen NMS G.2016.34.1, a left dentary, extends the known distribution of this genus to the Kilmaluag Formation of the Isle of Skye, Scotland, and adds to the faunal list for this locality.

Through morphological comparison, the molars remaining in the dentary provide strong evidence supporting the original identification of holotype specimen of $W$. rex as a lower left m1. NMS G.2016.34.1 indicates an apomorphic labial cingulid in Wareolestes rex, previously incorrectly identified as lingual cingulid. 
Replacement teeth within the dentary indicate a diphyodont replacement of the premolariform dentition. This supports previous evidence for such tooth replacement patterns in other morganucodontans, including Morganucodon, Megazostrodon and Dinnetherium. We find no evidence for replacement in m2, as suggested for Megazostrodon (Gow 1986).

Due to abrasion on the buccal portion of the dentary and loss of $p 1$ and $p 3$, we cannot clearly identify the sequence of dental replacement along the tooth row of NMS G.2016.34.1. However, the absence of a replacement p3 within the body of the dentary suggests possible alternating premolar replacement in Wareolestes, a character seen in some stem therians and eutherian mammals. We hope that further finds may clarify this. We emphasize the importance of ongoing field work and collection in the Kilmaluag Formation, and the wealth of data it adds to our understanding of Middle Jurassic mammaliaform diversity and the assembly of mammalian characters.

\begin{abstract}
Acknowledgements. We thank the John Muir Trust and Scottish Natural Heritage for access to the locality and permitting specimen collection. Specimens were scanned using funding from the European Union's Horizon 2020 research and innovation programme 2014-2018 under grant agreement 677774 (ERC Starting Grant: TEMPO) to RBJB. We thank Ketura Smithson (Department of Zoology, University of Cambridge) for assistance with CT scanning. We thank Pip Brewer from the Natural History Museum, London, for access to specimens. Thank you
\end{abstract}


to Pam Gill for many invaluable discussions. Finally we acknowledge our diligent field work teams for their hard work and keen eyes. We'd also like to thank our reviewers for their constructive comments and corrections.

\title{
DATA ARCHIVING STATEMENT
}

Data for this study are available in the Dryad Digital Repository: https://doi.org/10.5061/dryad.5n36j

\section{REFERENCES}

\begin{abstract}
ANDREWS, J. E. 1985. The sedimentary facies of a late Bathonian regressive episode: the Kilmaluag and Skudiburgh Formations of the Great Estuarine Group, Inner Hebrides, Scotland. Journal of the Geological Society of London, $142,1119-1137$.
\end{abstract}

\author{
BARRON, A. J. M., LOTT, G. K. and RIDING, J. B. 2012. Stratigraphical \\ framework for the Middle Jurassic strata of Great Britain and the adjoining \\ continental shelf. British Geological Survey, Nottingham, 177 pp.
}
BUTLER, P. M. and HOOKER, J. J. 2005. New teeth of allotherian mammals from the English Bathonian, including the earliest multituberculates. Acta Palaeontologica Polonica, 50, 185-207.


--- and SIGOGNEAU-RUSSELL, D. 2016. Diversity of triconodonts in the Middle Jurassic of Great Britain. Palaeontologia Polonica, 67, 35-65.

CLEMENS, W. A. 1980. Rhaeto-Liassic mammals from Switzerland and West Germany. Zitteliana, Abhandlungen der Bayerischen Staatssammlung für Paläontologie und Historische Geologie, 5, 51-92.

--- 2011 New morganucodontans from an Early Jurassic fissure filling in Wales. Palaeontology, 54, 1139-1156.

CLOSE, R. A., DAVIS, B. M., WALSH, S., WOLNIEWICZ, A. S., FRIEDMAN, M. and BENSON, R. B. 2016. A lower jaw of Palaeoxonodon from the Middle Jurassic of the Isle of Skye, Scotland, sheds new light on the diversity of British stem therians. Palaeontology, 59, 155-169.

CROMPTON, A. W. 1964. A preliminary description of a new mammal from the Upper Triassic of South Africa. Proceedings of the Zoological Society of London, $142,441-452$.

--- 1974. The dentition and relationships of the southern African Triassic mammals, Erythrotherium parringtoni and Megazostrodon rudnaerae. Bulletin of the British Museum (Natural History), 24, 397-437. 
--- and JENKINS F. A. 1968. Molar occlusion in Late Triassic Mammals.

Biological Reviews, 43, 427-458.

--- and LUO Z.-X 1993. Relationships of the Liassic mammals Sinoconodon, Morganucodon and Dinnetherium. In SZALAY, F. S., NOVACEK, M. J. and MCKENNA, C. (eds). Mammals Phylogeny: Mesozoic Differentiation, Multituberculates, Monotremes, Early Therians and Marsupials. Springer-verlag, New York, NY, 249 pp.

DATTA, P. M. and DAS, D. P 1996. Discovery of the oldest fossil mammal from India. Indian Minerals, 50, 217-222.

--- 2001. Indozostrodon simpsoni, gen. et sp. nov., an Early Jurassic megazostrodontid mammal from India. Journal of Vertebrate Paleontology, 21, 528-534.

DEBUYSSCHERE, M., GHEERBRANT, E. and ALLAIN, R. 2015. Earliest known European mammals: a review of the Morganucodonta from Saint-Nicolas-de-Port (Upper Triassic, France). Journal of Systematic Palaeontology, 13, 825-855.

EVANS, S. E. and MILNER, A. R. 1994. Middle Jurassic microvertebrate assemblages from the British Isles. In FRASER, N. C. and SUES, H. (eds). In the 
shadow of the dinosaurs: Early Mesozoic tetrapods. Cambridge University Press, Cambridge, 429 pp.

FREEMAN, E. F. 1979. A Middle Jurassic mammal bed from Oxfordshire. Palaeontology, 22, 135-166.

--- 1976. Mammal teeth from the Forest Marble (Middle Jurassic) of Oxfordshire, England. Science, 194, 1053-1055.

GAMBARYAN, P. P. and AVERIANOV, A. O. 2001. Femur of a morganucodontid mammal from the Middle Jurassic of central Russia. Acta Palaeontologica Polonica, 46, 99-112.

GOW, C. E. 1986. A new skull of Megazostrodon (Mammalia, Triconodonta) from the Elliot Formation (Lower Jurassic) of southern Africa. Palaeontologia Africana, 26, 13-23.

HAHN, G., SIGOGNEAU-RUSSELL, D. and GODEFROIT, P. 1991. New data on Brachyzostrodon (Mammalia; Upper Triassic). Geologica et Paleontologica, 25, 237-249. 
HUDSON, J. D. 1980. Aspects of brackish-water facies and faunas from the Jurassic of north-west Scotland. Proceedings of the Geologists' Association, 91, 99-105.

JÄGER, K., GILL, P., CORFE, I. J., MARTIN, T. 2016. 3D analysis of the chewing cycle and dental occlusion of Morganucodon watsoni. 160. In FARKE, A., MACKENZIE, A. and MILLER-CAMP, J. (eds). Society for Vertebrate Palaeontology 76th Annual Meeting: Meeting Programme and Abstracts. Salt Lake City, UT, USA.

JENKINS, F. A., CROMPTON, A. W. and DOWNS, W. R. 1983. Mesozoic mammals from Arizona: new evidence on mammalian evolution. Science, 222, 1233-1235.

-- SHUBIN, N. H., AMARAL, W. W., GATESEY, S. M., SCHAFF, C. R., CLEMMENSEN, L. B., DOWNS, W. R., DAVIDSON, A., BONDE, N. and OSBAECK, F. 1994. Late Triassic continental vertebrates and depositional environments of the Fleming Fjord Formation, Jameson Land, East Greenland. Meddelelser on Grønland, 32, 3-25.

KERMACK, K. A., MUSSET, F. and RIGNEY, H. W. 1973. The lower jaw of Morganucodon. Zoological Journal of the Linnean Society, 53, 87-175. 
--- KERMACK, D. M., LEES, P. M. and MILLS, J. R. 1998. New multituberculatelike teeth from the Middle Jurassic of England. Acta Palaeontologica Polonica, 43, 581-606.

KIELAN-JAWOROWSKA, Z., CIFELLI, R. L. and LUO, Z.-X. 2004. Mammals from the age of dinosaurs: origins evolution and structure. Columbia University Press, New York, NY, 630 pp.

LAUTENSCHLAGER, S., GILL, P., LUO, Z.-X., FAGAN, M. J. and RAYFIELD, E. 2016. Morphological evolution of the mammalian jaw adductor complex. Biological Reviews.

LUO, Z.-X. 1994. Sister group relationships of mammals and transformation of diagnostic mammalian characters. In FRASER, N. C. and SUES, H. (eds). In the shadow of the dinosaurs: Early Mesozoic tetrapods. Cambridge University Press, Cambridge, 429 pp.

--- 2011. Developmental patterns in Mesozoic evolution of mammal ears. Annual Review of Ecology, Evolution and Systematics, 42, 355-380.

--- and WU, X. 1994. The small tetrapods of the lower Lufeng Formation, Yunnan, China. In FRASER, N. C. and SUES, H. (eds). In the shadow of the 
dinosaurs: Early Mesozoic tetrapods. Cambridge University Press, Cambridge, 429 pp.

--- KIELEN-JAWOROWSKA, Z. and CIFELLI, R. L. 2004. Evolution of dental replacement in mammals. Bulletin of the Carnegie Museum of Natural History, 36, 159-175.

MCKENNA, M. C. and BELL S. K. 1997. Classification of Mammals Above the Species Level. Columbia University Press, New York, NY, 640 pp.

MENG, Q.-J., JI, Q., Zhang, Y.-G., Liu, D., Grossnickle, D.M., and LUO, Z.-X. 2015. An arboreal docodont from the Jurassic and mammaliaform ecological diversification. Science, 347: 764-768.

MILLS, J. R. E. 1971. The dentition of Morganucodon. In KERMACK, K. A. and KERMACK, D. M. (eds). Early Mammals. Academic Press, London, 198 pp.

O'MEARA, R. N. and ASHER, R. J. 2016. The evolution of growth patterns in mammalian versus nonmammalian cynodonts. Paleobiology, 42:439-464.

PACEY, D. 1978. On a tetrapod assemblage from a Mesozoic fissure fill, South Wales. Unpublished PhD Thesis, University College of London, London, 273 pp. 
PANCIROLI, E., BENSON, R. B. J. and WALSH, S. 2017. Data from: The dentary of Wareolestes rex (Megazostrodontidae): a new specimen from Scotland and implications for morganucodontan tooth replacement. Dryad Digital Repository. https://doi.org/10.5061/dryad.5n36j

PARRINGTON, F. R. 1967. The origins of mammals. Advancements in science, 24, 165-173.

--- 1971. On the Upper Triassic mammals. Philosophical Transactions of the Royal Society of London, Series B, 261, 231-272.

--- 1973. The dentitions of the earliest mammals. Zoological Journal of the Linnean Society, 52, 85-95.

PRASAD G. R. and MANHAS, B. K. 2002. Triconodont mammals from the Jurassic Kota Formation of India. Geodiversitas 24, 445-464.

--- VERMA, O. and PARMAR, V. 2006. An overview of the Mesozoic mammalian fauna of India. 101-104. In BARRET, P. M. and EVANS, S. E. (eds). Ninth International Symposium on Mesozoic Terrestrial Ecosystems and Biota. Manchester, UK. 
ROWE, T. B. 1988. Definition, diagnosis, and origin of Mammalia. Journal of Vertebrate Paleontology, 8, 241-264.

SAVAGE, R. J. G. 1984. Mid Jurassic mammals from Scotland. 211-213. In

REIF, W. E. and WESTPHAL, F. (eds). Third Symposium on Mesozoic

Terrestrial Ecosystems, Tübingen, Germany.

SIGOGNEAU-RUSSELL, D. 1983. A new therian mammal from the Rhaetic locality of Saint-Nicolar-de-Port (France). Zoological Journal of the Linnean Society, $\mathbf{7 8}, 175-186$.

--- 1998. Discovery of a Late Jurassic Chinese mammal in the upper Bathonian of England. Comptes Rendus de I'Académie des Sciences-Series IIA-Earth and Planetary Science, 327, 571-576.

--- 2003. Holotherian mammals from the Forest Marble (Middle Jurassic of England). Geodiversitas, 25, 501-537.

STUCKY, R. K. and MCKENNA, M. C. 1993. Mammalia. In Benton, M. J. (ed.). The Fossil Record 2. Chapman \& Hall, London, 846 pp.

WALDMAN, M. and SAVAGE, R. J. G. 1972. The first Jurassic mammal from Scotland. Journal of the Geological Society, 128, 119-125. 
YOUNG, C. C. 1978. New material of Eozostrodon. Vertebrata PalAsiatica, 16, 13.

ZHANG, F., CROMPTON, A. W., LUO, Z.-X. and SCHAFF, C. R. 1998. Pattern of dental replacement of Sinoconodon and its implications for evolution of mammals. Vertebrata Pal-siatica, 36, 197-217.

Figure 1: Megazostrodontidae cusp terminology. A, holotype Wareolestes rex NHMUK PV M36525 as an upper molar, lingual view. B, holotype Wareolestes NHMUK PV M36525 as an upper molar, labial view. C, holotype NHMUK PV M36525 as a lower molar as originally described, lingual view. D, segmented tooth from new specimen NMS G.2016.34.1 in labial view. Light shading indicates loss of enamel, dark shading missing portion of tooth. Arrow indicates anterior direction. Scale bar equals $1 \mathrm{~mm}$.

Figure 2: New specimen of Wareolestes rex, NMS G.2016.34.1 with comparative material. A, buccal view of Wareolestes rex, NMS G.2016.34. B, line drawing of Wareolestes rex, NMS G.2016.34, reduced in size for comparison with corresponding portions of C and D. C, line drawing of buccal view of Dinnetherium nezorum. D, line drawing of buccal view of Megazostrodon rudnerae. Sources: C, composite drawing from Gow (1986) and Keilan- 
Jaworowska et al. (2004); D, composite drawing from Jenkins et al. (1983) and Keilan-Jaworowska et al. (2004). Scale bar equals $1 \mathrm{~mm}$.

Figure 3: Segmentation and digital reconstruction of the new specimen of Wareolestes rex G.2016.34.1 from $\mu$ CT scan data. A, lingual view of dentition. B, lingual view of dentary. C, occlusal view of dentition. D, occlusal view of dentary. $E$, buccal view of dentition. $F$, buccal view of dentary with replacement pattern in Wareolestes underneath. G, dp2/p2 enlarged, showing deciduous premolar outlined in dotted line (blue), replacement premolar cusp $a$ in solid line (red). $p=$ premolar, $\mathrm{dp}=$ deciduous premolar, $\mathrm{m}=$ molar. Arrows indicate anterior direction . Scale bar equals $1 \mathrm{~mm}$.

Figure 4: Detail of features of NMS G.2016.34.1. A, buccal view of the anterior of the dentary showing the single root alveoli followed by double root (see text). B, molarised morphology of the remnant of cingulid in p5. C, segmented pathway of the mandibular nerve within the dentary. Scale bars equal $1 \mathrm{~mm}$.

Figure 5: Comparisons between the reconstructed $\mu \mathrm{CT}$ scan of the holotype Wareolestes rex NHMUK PV M36525 as a lower molar, and m1 and m2 from NMS G.2016.34.1. A, buccal view of NHMUK PV M36525. B, buccal view of $m 1$ NMS G.2016.34.1. C, buccal view of m2 NMS G.2016.34.1. D, lingual view of NHMUK PV M36525. E, lingual view of $m 1$ NMS G.2016.34.1. F, lingual view of m2 NMS G.2016.34.1. G, occlusal view of NHMUK PV M36525. H, occlusal view 
of m1 NMS G.2016.34.1. I, occlusal view of m2 NMS G.2016.34.1. Grey areas indicate broken portions of tooth. Dotted lines indicate reconstructed features based on comparisons. Arrows indicate anterior direction. Scale bar equals 1 $\mathrm{mm}$.

Figure 6: Lower molar measurements for new specimen and comparative material (see Table 1). Mean measurement from multiple specimens used for Brachyzostrodon coupatezi, Bridetherium and Hallautherium. Includes largest (I) and smallest (s) measurements for Morganucodon watsoni from Pacey (1978).

Table 1: Measurements of new specimen and comparative data from Morganucodontidae. For partial teeth of Wareolestes rex, estimates were made conservatively. 


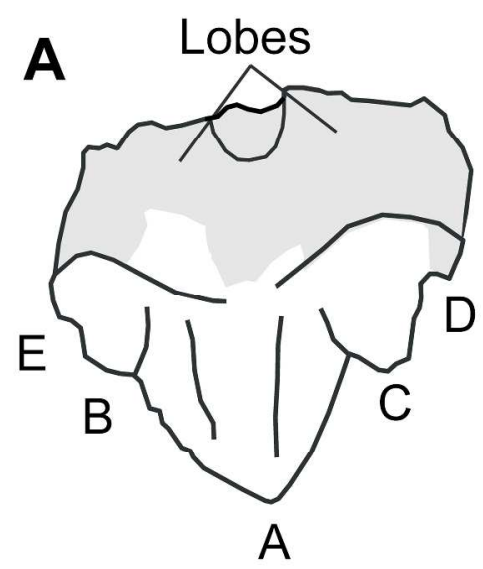

B
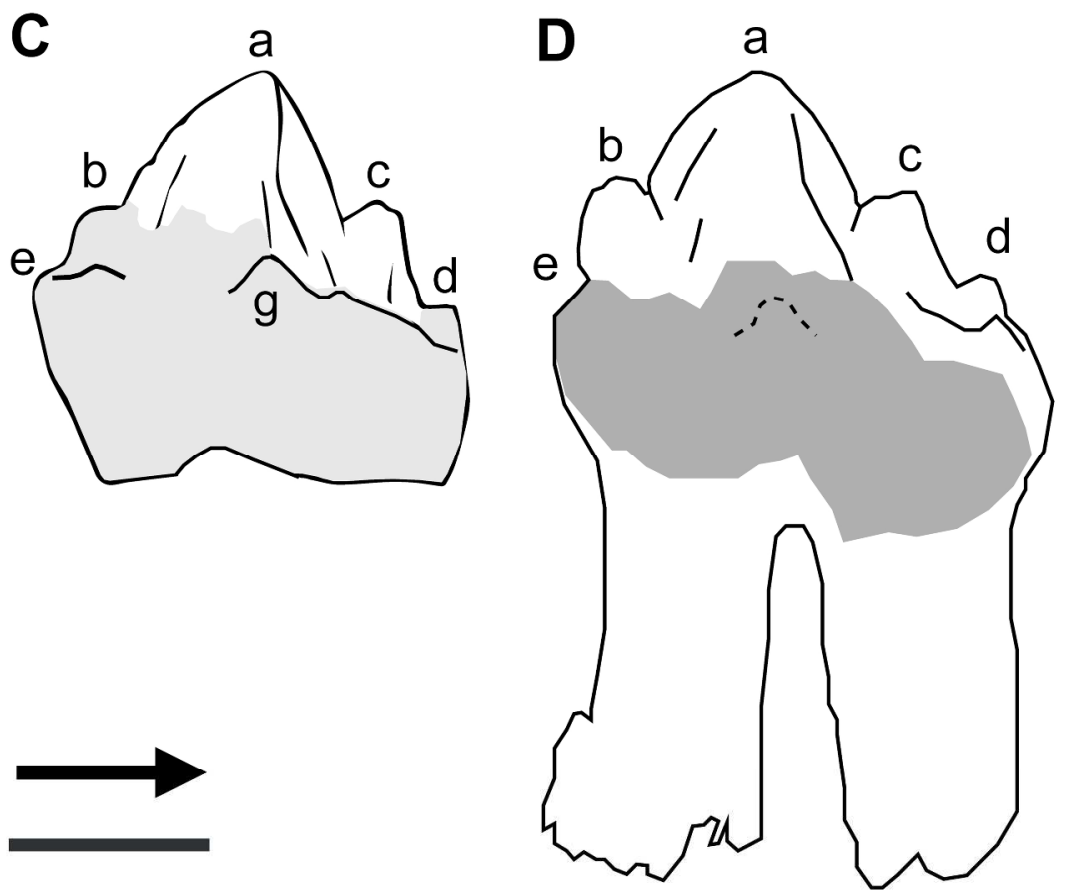

\begin{abstract}
Megazostrodontidae cusp terminology. A, holotype Wareolestes rex NHMUK PV M36525 as an upper molar, lingual view. B, holotype Wareolestes NHMUK PV M36525 as an upper molar, labial view. C, holotype NHMUK PV M36525 as a lower molar as originally described, lingual view. D, segmented tooth from new specimen NMS G.2016.34.1 in labial view. Light shading indicates loss of enamel, dark shading missing portion of tooth. Arrow indicates anterior direction. Scale bar equals $1 \mathrm{~mm}$.
\end{abstract}

Figure 1

$112 \times 158 \mathrm{~mm}(600 \times 600 \mathrm{DPI})$ 
New specimen of Wareolestes rex, NMS G.2016.34.1 with comparative material. A, buccal view of Wareolestes rex, NMS G.2016.34. B, line drawing of Wareolestes rex, NMS G.2016.34, reduced in size for comparison with corresponding portions of C and D. C, line drawing of buccal view of Dinnetherium nezorum. D, line drawing of buccal view of Megazostrodon rudnerae. Source: C, composite drawing from Gow (1986) and Keilan-Jaworowska et al. (2004). D, composite drawing from Jenkins et al. (1983) and Keilan-Jaworowska et al. (2004). Scale bar equals $1 \mathrm{~mm}$.

Figure 2

$175 \times 181 \mathrm{~mm}(300 \times 300 \mathrm{DPI})$ 

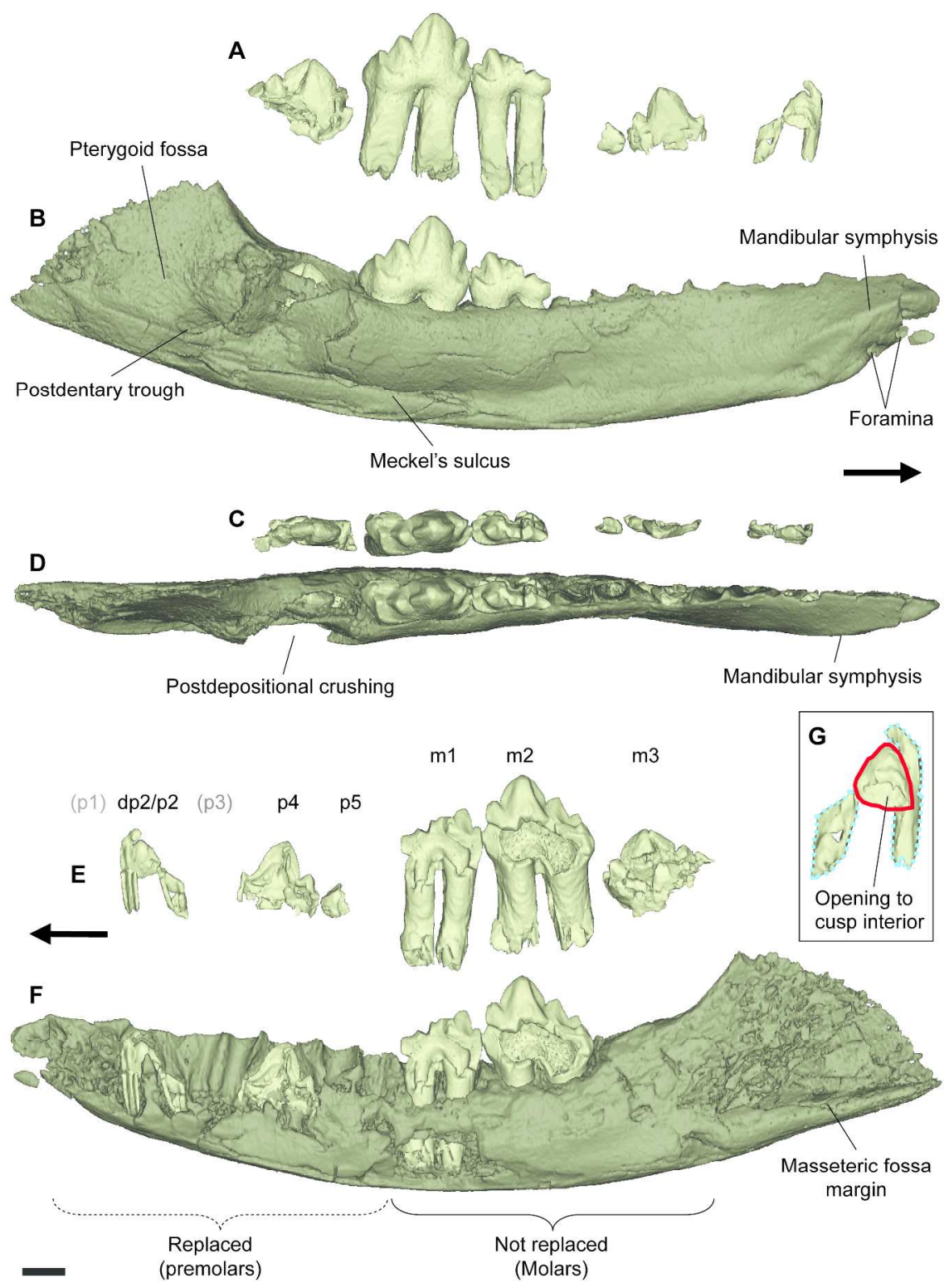

Segmentation and digital reconstruction of new Wareolestes rex G.2016.34.1 from $\mu$ CT scan data. A, lingual view of dentition. $B$, lingual view of dentary. $C$, occlusal view of dentition. $D$, occlusal view of dentary. $E$, buccal view of dentition. F, buccal view of dentary with replacement pattern in Wareolestes underneath. G, $\mathrm{dp} 2 / \mathrm{p} 2$ enlarged, showing deciduous premolar outlined in dotted line (blue), replacement premolar cusp a in solid line (red). $\mathrm{p}=$ premolar, $\mathrm{dp}=$ deciduous premolar, $\mathrm{m}=$ molar. Arrows indicate anterior direction. Scale bar equals $1 \mathrm{~mm}$.

Figure 3 $227 \times 312 \mathrm{~mm}(300 \times 300 \mathrm{DPI})$ 
Detail of features of NMS G.2016.34.1. A, buccal view of the anterior of the dentary showing the single root alveoli followed by double root (see text). B, molarised morphology of the remnant of cingulid in p5. C, segmented pathway of the mandibular nerve within the dentary. Scale bars equal $1 \mathrm{~mm}$.

Figure 4

$122 \times 90 \mathrm{~mm}(300 \times 300 \mathrm{DPI})$ 

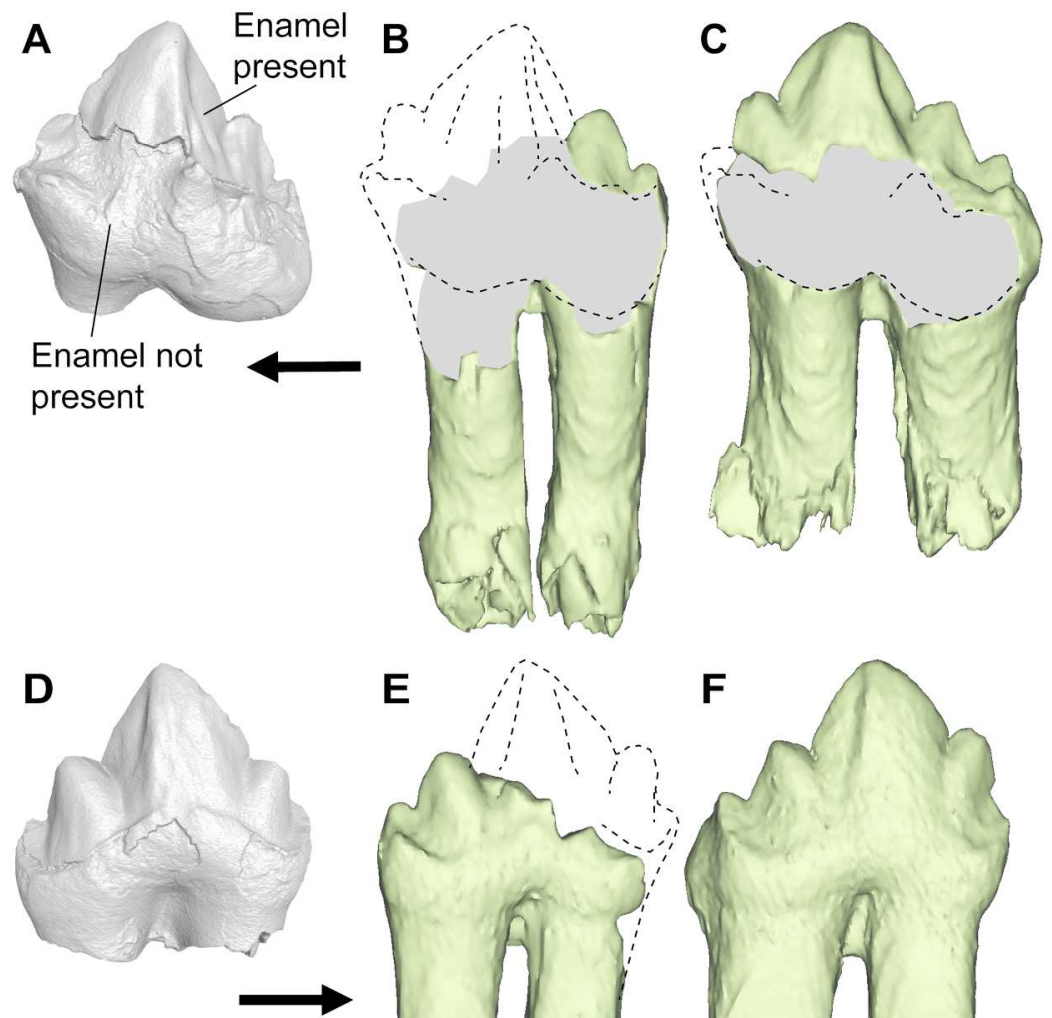

E

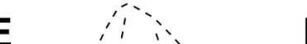

$F$
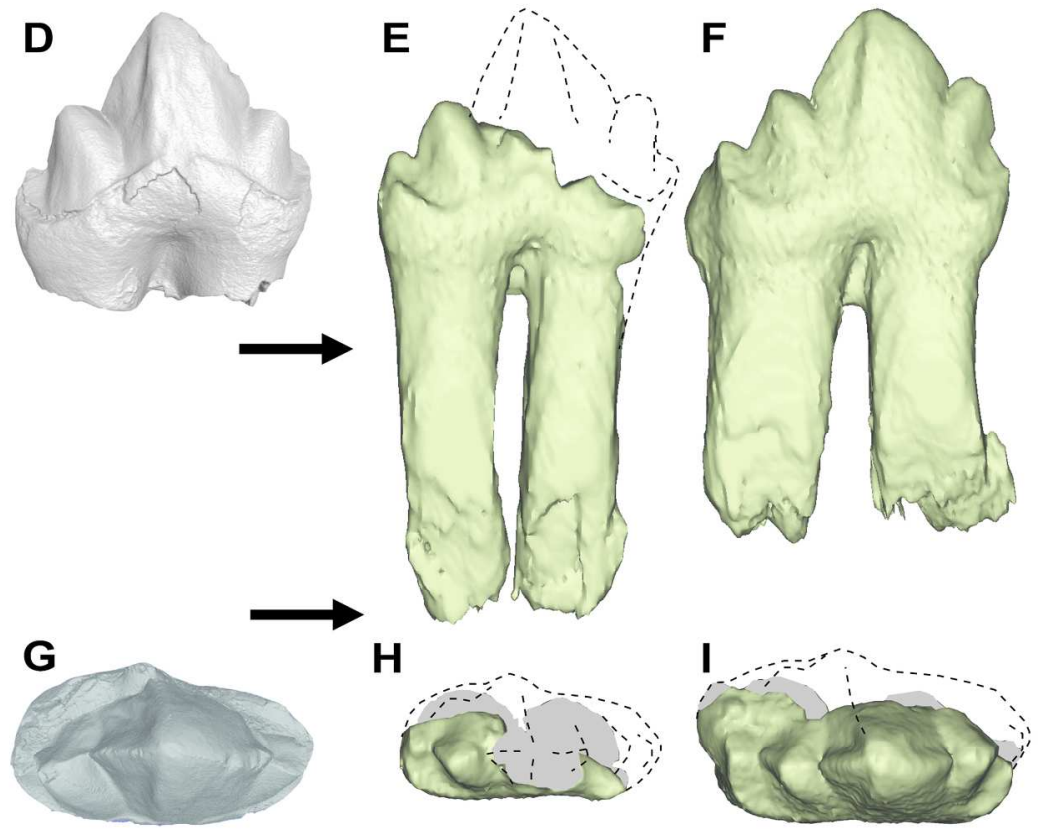

Comparisons between the reconstructed $\mu \mathrm{CT}$ scan of the holotype Wareolestes rex NHMUK PV M36525 as a lower molar, and $\mathrm{m} 1$ and $\mathrm{m} 2$ from NMS G.2016.34.1. A, buccal view of NHMUK PV M36525. B, buccal view of $m 1$ NMS G.2016.34.1. C, buccal view of m2 NMS G.2016.34.1. D, lingual view of NHMUK PV M36525. E, lingual view of $m 1$ NMS G.2016.34.1. F, lingual view of m2 NMS G.2016.34.1. G, occlusal view of NHMUK PV M36525. H, occlusal view of m1 NMS G.2016.34.1. I, occlusal view of m2 NMS G.2016.34.1. Grey areas indicate broken portions of tooth. Dotted lines indicate reconstructed features based on comparisons. Arrows indicate anterior direction. Scale bar equals $1 \mathrm{~mm}$.

Figure 5

$161 \times 238 \mathrm{~mm}(300 \times 300 \mathrm{DPI})$ 


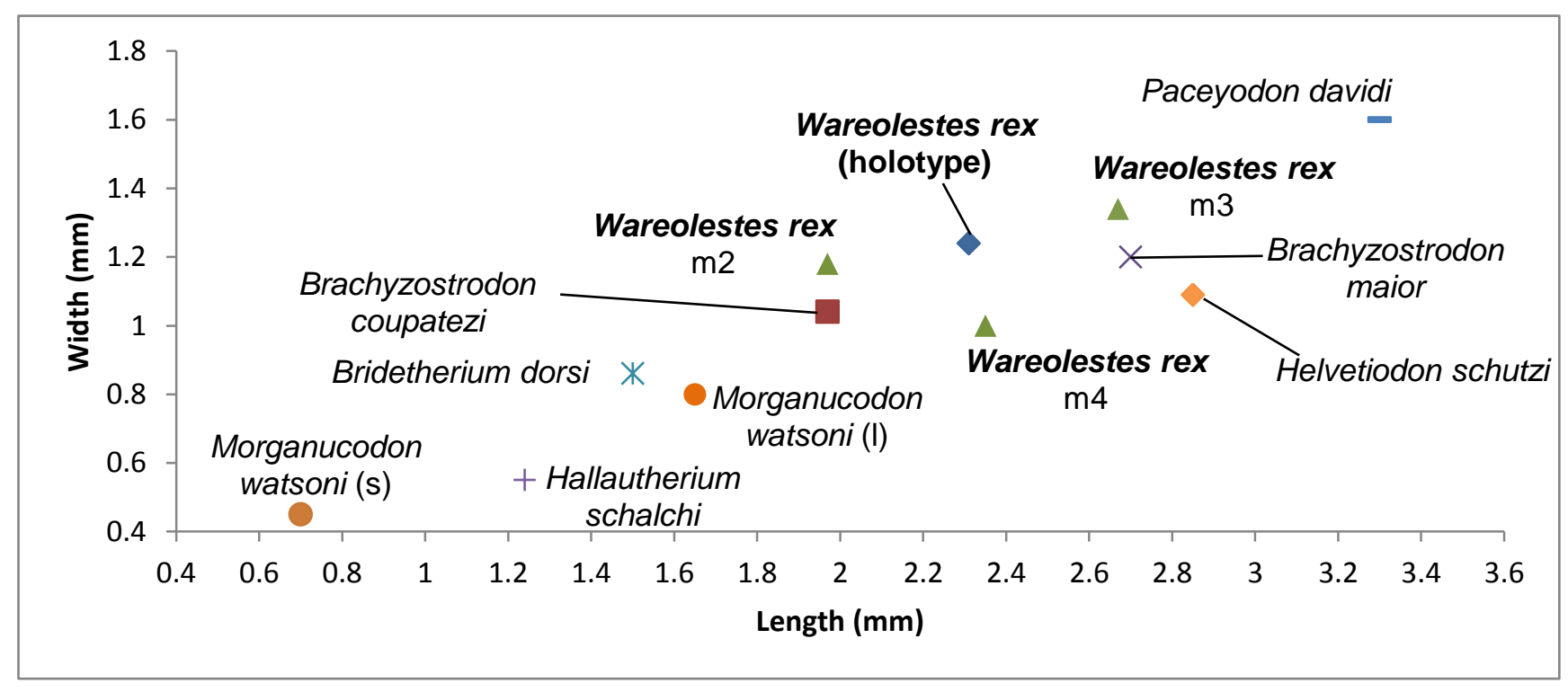


Table 1: Measurements of new specimen and comparative data from Morganucodontidae. For partial teeth of Wareolestes rex, estimates were made conservatively.

\begin{tabular}{|c|c|c|c|c|c|}
\hline Taxon & Dentition & $\begin{array}{l}\text { Specimen } \\
\text { No. }\end{array}$ & $\begin{array}{l}\text { Max } \\
\text { length } \\
(\mathrm{mm})\end{array}$ & $\begin{array}{l}\text { Max width } \\
\text { (mm) }\end{array}$ & Reference \\
\hline \multicolumn{6}{|l|}{ Megazostrodontidae } \\
\hline Wareolestes rex & Lower m2 & $\begin{array}{l}\text { NMS } \\
\text { G.2016.34.1. }\end{array}$ & $\begin{array}{r}1.97 \\
\text { (estimate) }\end{array}$ & $\begin{array}{r}1.18 \\
\text { (estimate) }\end{array}$ & \\
\hline Wareolestes rex & Lower m3 & $\begin{array}{l}\text { NMS } \\
\text { G.2016.34.1. }\end{array}$ & 2.67 & $\begin{array}{r}1.30 \\
\text { (estimate) }\end{array}$ & \\
\hline Wareolestes rex & Lower m4 & $\begin{array}{l}\text { NMS } \\
\text { G.2016.34.1. }\end{array}$ & $\begin{array}{r}2.35 \\
\text { (estimate) }\end{array}$ & $\begin{array}{r}1.0 \\
\text { (estimate) }\end{array}$ & \\
\hline Wareolestes rex & molar & $\begin{array}{l}\text { NHMUK PV } \\
\text { M36525 }\end{array}$ & 2.31 & 1.24 & $\begin{array}{l}\text { Freeman } \\
(1979)\end{array}$ \\
\hline $\begin{array}{l}\text { Brachyzostrodon } \\
\text { coupatezi }\end{array}$ & $\begin{array}{l}\text { lower } \\
\text { molars }\end{array}$ & Multiple & $1.75-2.15$ & $0.75-1.21$ & $\begin{array}{l}\text { Hahn et al. } \\
\text { (1991) }\end{array}$ \\
\hline $\begin{array}{l}\text { Brachyzostrodon } \\
\text { maior }\end{array}$ & $\begin{array}{l}\text { lower } \\
\text { molars }\end{array}$ & & 2.7 & 1.2 & $\begin{array}{l}\text { Hahn et al. } \\
\text { (1991) }\end{array}$ \\
\hline \multicolumn{6}{|l|}{ Morganucodontidae } \\
\hline Paceyodon davidi & $\begin{array}{l}\text { lower } \\
\text { molars }\end{array}$ & multiple & 3.3 & 1.6 & $\begin{array}{l}\text { Clemens } \\
(2011)\end{array}$ \\
\hline $\begin{array}{l}\text { Morganucodon } \\
\text { watsoni }\end{array}$ & $\begin{array}{l}\text { lower } \\
\text { molars }\end{array}$ & multiple & $0.70-1.65$ & $0.45-0.80$ & Pacey (1978) \\
\hline $\begin{array}{l}\text { Morganucodon } \\
\text { watsoni }\end{array}$ & $\begin{array}{l}\text { upper } \\
\text { molars }\end{array}$ & multiple & $0.80-1.60$ & $0.45-0.80$ & Pacey (1978) \\
\hline Morganucodon oehleri & $\begin{array}{l}\text { lower } \\
\text { molars }\end{array}$ & Multiple & $1.06-2.30$ & CUP 2320 & $\begin{array}{l}\text { Kermack et al. } \\
\text { (1973) }\end{array}$ \\
\hline Morganucodon oehleri & $\begin{array}{l}\text { upper } \\
\text { molars }\end{array}$ & Multiple & $1.40-2.30$ & CUP 2321 & $\begin{array}{l}\text { Kermack et al. } \\
\text { (1973) }\end{array}$ \\
\hline Hallautherium schalchi & $\begin{array}{l}\text { lower } \\
\text { molars }\end{array}$ & Multiple & $1.08-1.39$ & $0.44-0.66$ & $\begin{array}{l}\text { Clemens } \\
(1980)\end{array}$ \\
\hline Helvetiodon schutzi & upper molar & & 2.85 & 1.09 & $\begin{array}{l}\text { Clemens } \\
(1980)\end{array}$ \\
\hline \multicolumn{6}{|l|}{ Incertae sedis } \\
\hline Bridetherium dorsi & $\begin{array}{l}\text { lower } \\
\text { molars }\end{array}$ & Multiple & $0.85-1.90$ & $0.48-1.15$ & $\begin{array}{l}\text { Clemens } \\
(2011)\end{array}$ \\
\hline Bridetherium dorsi & $\begin{array}{l}\text { upper } \\
\text { molars }\end{array}$ & Multiple & $1.02-1.70$ & $0.55-0.96$ & $\begin{array}{l}\text { Clemens } \\
(2011)\end{array}$ \\
\hline
\end{tabular}

